\title{
Predictive Control for Earthquake Response Mitigation of Buildings Using Semiactive Fluid Dampers
}

\author{
F. Oliveira, ${ }^{1}$ P. Morais, ${ }^{1}$ and A. Suleman ${ }^{2,3}$ \\ ${ }^{1}$ Laboratório Nacional de Engenharia Civil (LNEC), Avenida do Brasil 101, 1700-066 Lisboa, Portugal \\ ${ }^{2}$ Department of Mechanical Engineering, University of Victoria, P.O. Box 1700 STN CSC, Victoria, BC, Canada V8W 2 Y 2 \\ ${ }^{3}$ Institute of Mechanical Engineering (IDMEC/IST), Avenida Rovisco Pais 1, 1049-001 Lisbon, Portugal \\ Correspondence should be addressed to F. Oliveira; fvoliveira@lnec.pt
}

Received 12 July 2013; Accepted 5 February 2014; Published 7 July 2014

Academic Editor: Nuno Maia

Copyright (C) 2014 F. Oliveira et al. This is an open access article distributed under the Creative Commons Attribution License, which permits unrestricted use, distribution, and reproduction in any medium, provided the original work is properly cited.

\begin{abstract}
A predictive control strategy in conjunction with semiactive control algorithms is proposed for damping control of base-isolated structures employing semiactive fluid dampers when subjected to earthquake loads. The controller considers the delays resulting from the device's dynamics and an observer for state estimation. Twenty artificial accelerograms were generated according to the Eurocode 8 for the Portuguese territory and considered for the numerical simulations of the base-isolated structure representative model. The results of a parametric study on a single degree of freedom model provide an indication for controller design in this type of problems. To evaluate the effectiveness of the proposed strategies, the response of a 10-storey base-isolated dual framewall building employing semiactive systems is compared with the original, passive solution and with an earlier proposed optimal controller for this type of problems. It is shown that a well-tuned controller could outperform the original structure, the structural system with a passive device (optimized) as well as with the semiactive optimal controller, in terms of relative displacement and absolute acceleration reductions.
\end{abstract}

\section{Introduction}

Civil engineering structures are usually built as passive structures with no adaptability to uncertain dynamic loads like earthquakes [1]. For structures that should be operational during and immediately after the occurrence of those events, such as hospitals, energy power stations, communication centres, civil protection, and fire station buildings, among others, special precautions should be taken. It is intended that structural relative displacements (interstorey drifts) and accelerations are small in order to avoid damage and protect sensitive equipments from induced vibrations $[2,3]$. New systems integrated in structures have been proposed to protect them against earthquakes with passive, semiactive, and active control technologies [4].

Semiactive (SA) control systems have received much attention in recent years due to some notable advantages: capacity of adapting its characteristics in real time, better overall performance when compared with passive devices, and lower operational power requirements, thus allowing for battery operation. Semiactive devices are seen as controllable passive devices that allow for adjustment of its mechanical characteristics (damping, stiffness) in real time [5]. Magnetorheological (MR) and fluid viscous dampers (FVD) are typical examples of semiactive devices. MR fluids consist of micron-sized particles in a carrier fluid (usually oil) whose characteristics can be reversibly changed from a free-flowing to a semisolid in milliseconds when subjected to a magnetic field $[5,6]$. A lot of investigations on this subject have been done in the last years and several applications can be found today [7-14]. The second type of devices (FVD) consists typically of a hydraulic cylinder filled with oil with a piston head separating its two chambers. A hydraulic link with a control valve is used to control the amount of fluid that flows from one chamber to the other $[5,6]$. Research projects and investigation with semiactive oil dampers are being made since the 1990s and many applications with these devices can be found all around the world, and especially in Japan $[7,15-$ 21]. In order to control the device's behaviour several control strategies have been proposed: (i) sky-hook control [6], 


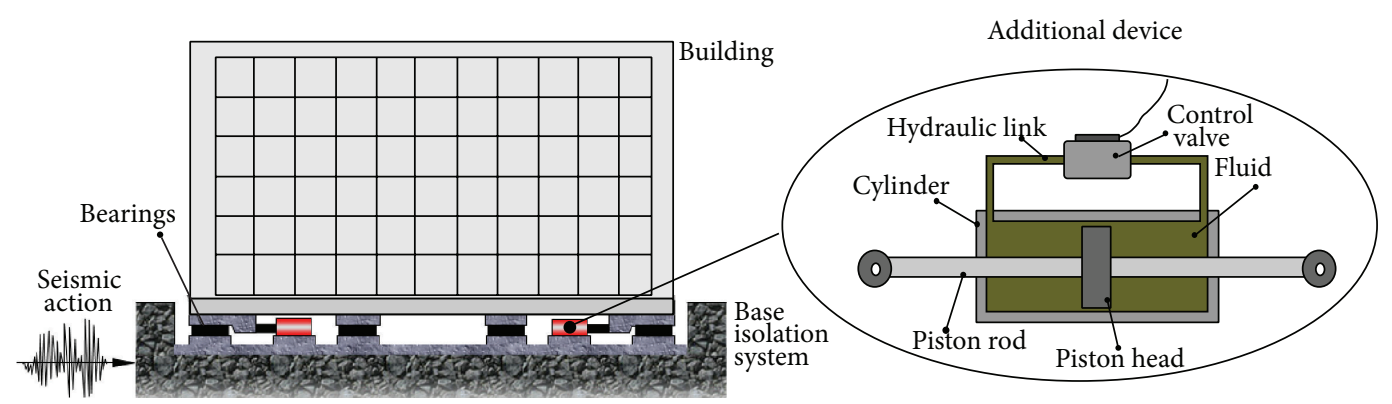

FIGURE 1: Hybrid system: base-isolated structure with semiactive fluid viscous damper.

(ii) optimal control $[8,9,15,16]$, (iii) control based on the Lyapunov stability theory [8], (iv) bang-bang control [8], (v) modulated homogeneous friction control algorithm [8], (vi) sliding mode control [15, 17], (vii) fuzzy logic [9], (viii) neural-network-based control [9], (ix) proportional plus integral control [10], (x) force derivative feedback control [11], quantitative feedback theory [12], and backstepping control technique [12].

In order to accomplish those goals (reduce both accelerations and interstorey drifts) the base isolation concept has been considered $[2,3]$. However, under near field seismic actions, base-isolated structures could face large displacements at the base due to pulse-like ground motions which make them vulnerable to structural damage [3]. An alternative solution would be the use of hybrid systems. Base isolation systems with passive devices like fluid viscous dampers have been proposed and experimentally verified to meet those goals $[3,22,23]$. Other approaches consisting of base isolation with semiactive devices have also been proposed to further improve more the system performance $[9,11,16,17]$.

Predictive control is a strategy that has been successfully implemented in petrochemical and process industry [24] and is considered here for an application in semiactive control. In this communication a variable fluid viscous damper is studied for reducing vibrations in civil engineering structures subjected to earthquakes using a predictive control strategy. The results of numerical simulations using representative models (single and multidegree of freedom models-SDOF and MDOF) of typical building structures employing a semiactive device excited by seismic actions at the base are presented. Comparisons with the original structure, with passive control and the optimal controller, show the potential of using this strategy.

\section{Problem Formulation}

The reduction of vibrations induced by earthquakes in structures consists in adding damping by means of variable damping devices whose damping characteristics are controlled by a predictive control strategy. Although several ways for installation of these devices can be found [5], we will consider a hybrid system consisting of SA devices in conjunction with base isolation systems (Figure 1).
A satisfactory approach usually considered in the building's modelling is that (i) each floor has very high stiffness where the mass is concentrated; (ii) the connections between floors are massless elements where the stiffness and damping are concentrated. In base-isolated structures the superstructure is constructed over a base floor which in turn is supported by bearings. For the purpose of this study bearings are modelled as linear elastic and viscous damping elements. A simple model that represents the key responses of civil engineering structures including the base isolation system can be described by the mass $\mathbf{M}_{s}$, stiffness $\mathbf{K}_{s}$, and damping $\mathbf{C}_{s}$ matrices. Considering the input ground motion (acceleration) $\ddot{x}_{g}$ and the force $f$ developed by the additional devices at the base, then the mechanical behaviour can be represented by a $n$ degree of freedom model (base plus $n-1$ floors):

$$
\mathbf{M}_{s} \cdot \ddot{\mathbf{x}}_{r g}+\mathbf{C}_{s} \cdot \dot{\mathbf{x}}_{r g}+\mathbf{K}_{s} \cdot \mathbf{x}_{r g}=-\mathbf{M}_{s} \cdot \mathbf{1} \cdot \ddot{x}_{g}+\mathbf{G} \cdot f,
$$

where $\mathbf{1}$ is a unitary column vector; $\mathbf{G}$ is the matrix that defines the input force location (for the present case $\mathbf{G}=$ $\left[\begin{array}{llll}-1 & 0 & \cdots & 0\end{array}\right]^{T}$, where the minus sign means that the force is dissipative); and $\mathbf{x}_{r g}$ is the vector of relative displacements to the ground. Additional damping is added at the base level by additional devices, which can be passive, active, or semiactive. The semiactive fluid viscous damper was considered and its behaviour was described by the viscous dashpot model with a variable damping coefficient $[4,15]$. However, to include the dynamic behaviour of the damper one must account the time response associated with its operation (the time to develop the damping force after the command to change the damping coefficient) $[15,17]$. In this type of devices the time response results in both valve dynamics and hydraulic system dynamics. The total response time can be described as the sum of pure time delays (or dead time) and lag (or phase delay), which are designated in [15] as static and dynamic response time, respectively. In [17] the total time response is treated as time lag. Time delays can change during operation (as damping increases or decreases) and an average time delay considering both operation processes is usually taken. In this work the device total time response (or delay) is accounted as lag and thus the viscous model is complemented with a first-order dynamic system which results in the Maxwell model:

$$
T_{d} \cdot \dot{f}+f=c_{v} \cdot \dot{x}_{r}, \quad c_{\min } \leq c_{v} \leq c_{\max },
$$


where $T_{d}$ is the relaxation time, or time constant representing an average of the device time response; $f$ is the damping force; $c_{v}$ is the damping coefficient which can be changed between a minimum and a maximum value; and $\dot{x}_{r}$ is the relative velocity between the cylinder case and the piston head of the damper.

The system described by (1) can be represented in the state-space form by

$$
\begin{aligned}
& \dot{\mathbf{z}}=\mathbf{A} \cdot \mathbf{z}+\mathbf{B} \cdot f+\mathbf{E} \cdot \ddot{x}_{g}, \\
& \mathbf{y}=\mathbf{C} \cdot \mathbf{z}+\mathbf{D} \cdot f, \\
& \mathbf{A}=\left[\begin{array}{cc}
\mathbf{0}_{n \times n} & \mathbf{I} \\
-\mathbf{M}_{s}^{-1} \cdot \mathbf{K}_{s} & -\mathbf{M}_{s}^{-1} \cdot \mathbf{C}_{s}
\end{array}\right], \\
& \mathbf{B}=\left[\begin{array}{c}
\mathbf{0}_{n \times 1} \\
-\mathbf{M}_{s}^{-1} \cdot \mathbf{G}
\end{array}\right], \quad \mathbf{E}=\left[\begin{array}{c}
\mathbf{0}_{n \times 1} \\
-\mathbf{1}
\end{array}\right],
\end{aligned}
$$

where $\mathbf{z}=\left\{\mathbf{x}_{r g}, \dot{\mathbf{x}}_{r g}\right\}^{T}$ is the state vector; $\mathbf{C}$ and $\mathbf{D}$ are defined according to the quantities for output; for instance, if $\mathbf{C}=$ $\mathbf{A}$ and $\mathbf{D}=\mathbf{B}$ the outputs will be the relative velocities and absolute accelerations; $\mathbf{0}, \mathbf{I}$, and $\mathbf{1}$ are a null matrix, identity matrix, and unitary vector, respectively.

\section{Vibration Control}

Figure 2 depicts the control loop considered in this work. The force tracking control scheme makes use of a controller and an algorithm to find the desired damping coefficient. The idea is that the device's force $f$ follows the desired force $f_{d}$ evaluated by the controller. A model predictive controller (MPC) is used to find the desired control force. According to the nature of the device, the algorithm assumes that it is only possible to dissipate energy, and thus the damping coefficient will be changed only when the desired force and damper force have the same sign. With this strategy a linear model of the plant (3) can be used and thus the calculation of the desired force is relatively straightforward [24]. In Figure 2 SW determines the algorithm considered: with or without feedback from the measured force.

3.1. Model Predictive Control Formulation. The MPC block in Figure 2 uses the predictive control strategy based on a linear model of the plant. The controller is formulated in the discrete domain and the idea consists in predicting future outputs from actual measurements and past inputs using the plant's model (predictor), comparing those outputs with the reference values, and determining a sequence of input trajectories that result from the solution of an optimization problem (optimizer). Only the first input is applied to the plant, and then the whole cycle of measurement, prediction, and input calculation is repeated in the next sampling interval (receding horizon). Since the states are not always available, this strategy uses an observer to estimate the remaining states (observer).

In the control loop of Figure 2 time delays can result from the process of measurement, input computation, and input

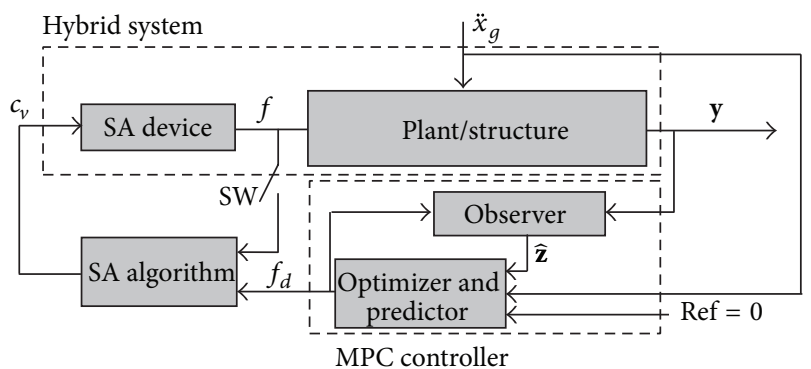

FIGURE 2: Proposed control loop: force tracking scheme using a MPC controller with a semiactive (SA) algorithm.

application. The prediction model used in the MPC block considers input delays since input action $f$ generated at time $t-T_{d}$ ( $T_{d}$ is the device time delay) only takes effect at time $t$, due to delays resulting from the force application (device). In the present case, the MPC block will generate a desired force $f_{d}(k-d)$ that will result in a force $f(k)$ applied by the device $d=T_{d} / T_{s}$ instants later ( $T_{s}$ is the sampling time), mainly due to the time response of the SA device. Thus, the following relationship is considered in the controller formulation: $f(k)=f_{d}(k-d)$. Measurement delays are assumed to be small when compared to the input application delays and thus are not considered in the formulation. Moreover, the computations are assumed to occur during the control interval $T_{s}$ (or sampling period). When converting this model to the discrete domain additional states are added. Then the MPC block internal model in the state-space discrete-time form is given by

$$
\begin{aligned}
\mathbf{z}_{a}(k+1) & =\mathbf{A}_{a} \cdot \mathbf{z}_{a}(k)+\mathbf{B}_{a} \cdot f_{d}(k)+\mathbf{E}_{a} \cdot a_{g}(k), \\
\mathbf{y}(k) & =\mathbf{C}_{a} \cdot \mathbf{z}_{a}(k),
\end{aligned}
$$

where $k$ is the time step derived from the discretisation process with a sampling time $T_{s} ; \mathbf{z}_{a}(k)=\left\{(\mathbf{z}(k))^{T}, f_{d}(k-\right.$ $\left.d), \ldots, f_{d}(k-1)\right\}^{T}$ is the state vector (dimension $n_{a} \times 1$ ) including relative displacements and velocities, and the past instant desired forces $f_{d}(k-i), i=1,2, \ldots, d ; f_{d}(k)$ is the actual desired force (scalar); $a_{g}(k)$ is the input ground motion (scalar); $\mathbf{y}(k)$ is the output vector (dimension $m_{a} \times 1$ ); and $\mathbf{A}_{a}$, $\mathbf{B}_{a}, \mathbf{E}_{a}$, and $\mathbf{C}_{a}$ are the discretized state-space model matrices. Using this model to predict the behaviour of the system for a specific prediction horizon (HP steps) and considering that the input force remains constant after a specific control horizon (HC steps), then the output predictions are given by the following equation [24]:

$$
\begin{aligned}
\mathbf{Y}(k)= & \boldsymbol{\Psi} \cdot \widehat{\mathbf{z}}_{a}(k \mid k)+\mathbf{T} \cdot f_{d}(k-1) \\
& +\boldsymbol{\Theta} \cdot \Delta \mathbf{F}_{d}(k)+\boldsymbol{\Xi} \cdot \mathbf{A}(k),
\end{aligned}
$$

where $\mathbf{Y}(k)=\left\{(\widehat{\mathbf{y}}(k+1 k))^{T}, \ldots,(\widehat{\mathbf{y}}(k+\mathrm{HP} k))^{T}\right\}^{T}$ is the vector (dimension $m_{a} \cdot \mathrm{HP} \times 1$ ) of output predictions at instant $k$ for instant $k+1$ to $k+\mathrm{HP} ; \widehat{\mathbf{z}}_{a}(k \mid k)$ is the estimated state vector at instant $k$ (when the full state vector is not available); $\Delta \mathbf{F}_{d}(k)=\left\{\Delta \widehat{f}_{d}(k \mid k), \ldots, \Delta \widehat{f}_{d}(k+\mathrm{HC}-1 \mid k)\right\}^{T}$ is the vector (dimension $\mathrm{HC} \times 1$ ) of future force input moves; 
$\Delta f_{d}(k)=f_{d}(k)-f_{d}(k-1) ; \mathbf{A}(k)=\left\{a_{g}(k), \widehat{a}_{g}(k \mid k), \ldots, \widehat{a}_{g}(k+\right.$ $\mathrm{HP}-1 \mid k)\}^{T}$ is the vector (dimension $\mathrm{HP} \times 1$ ) of measured and future disturbances (commonly assumed as constant and equal to the last measured value $a_{g}(k)$ ); and $\boldsymbol{\Psi}, \mathbf{T}, \boldsymbol{\Theta}$, and $\boldsymbol{\Xi}$ are constant matrices derived from the plant's model: $\Psi=\mathscr{C}_{a} \cdot \mathscr{A}$; $\mathrm{T}=\mathscr{C}_{a} \cdot \mathscr{B} ; \Theta=\mathscr{C}_{a} \cdot \mathscr{H} ; \Xi=\mathscr{C}_{a} \cdot \mathscr{E} ;$ with

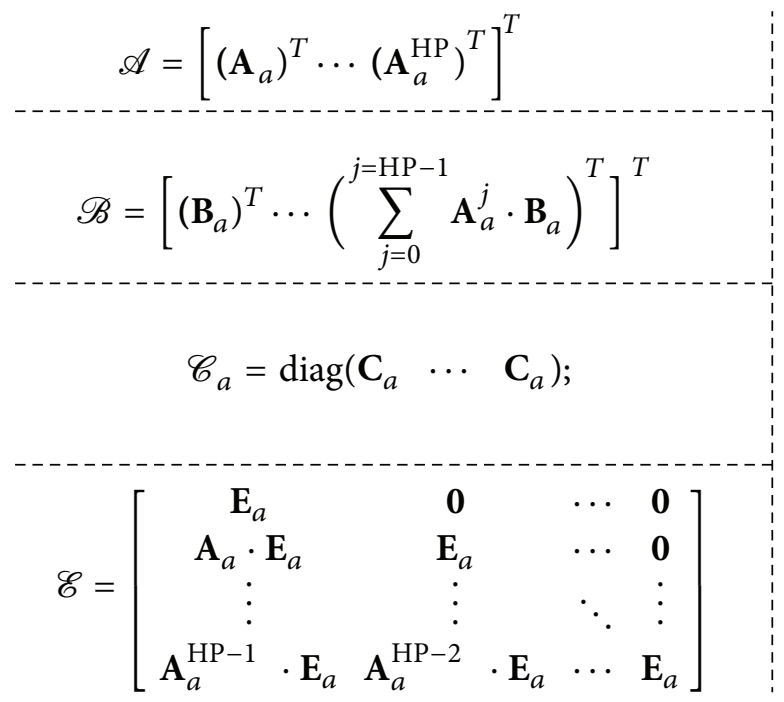

The optimal input force moves can be obtained as the solution of an unconstrained optimization problem (minimization) with the following cost function [24]:

$$
\begin{aligned}
V(k)= & \sum_{i=1}^{\mathrm{HP}}\|\widehat{\mathbf{y}}(k+i \mid k)\|_{\mathrm{Q}}^{2} \\
& +\sum_{i=0}^{\mathrm{HC}-1}\left\|\Delta \widehat{f}_{d}(k+i \mid k)\right\|_{R}^{2}=\|\mathbf{Y}(k)\|_{\mathscr{Q}}^{2}+\left\|\Delta \mathbf{F}_{d}(k)\right\|_{\mathscr{R}}^{2},
\end{aligned}
$$

where $Q$ is the matrix (dimension $m_{a} \times m_{a}$ ) that weights the outputs and $R$ (dimension $1 \times 1$ ) weights the input moves; $Q$ is the compound weight matrix (dimension $m_{a} \cdot \mathrm{HP} \times m_{a} \cdot \mathrm{HP}$ ) with the weighting matrices $Q$ in the diagonal; and $\mathscr{R}$ is the compound weight matrix (dimension $\mathrm{HC} \times \mathrm{HC}$ ) with $R$ in the diagonal. The solution of this optimization problem can be obtained by finding the gradient of the cost function and set it to zero:

$$
\begin{aligned}
\Delta \mathbf{F}_{d}(k) & =\frac{1}{2} \mathscr{H}_{\text {term }}^{-1} \cdot \mathscr{G}_{\text {term }}, \\
\text { with } \mathscr{H}_{\text {term }} & =\boldsymbol{\Theta}^{T} \cdot \mathcal{Q} \cdot \boldsymbol{\Theta}+\mathscr{R}, \\
\mathscr{G}_{\text {term }} & =2 \cdot \Theta^{T} \cdot \mathcal{Q} \cdot \mathbf{E}(k),
\end{aligned}
$$

where $\mathbf{E}(k)=-\mathbf{\Psi} \cdot \widehat{\mathbf{z}}_{a}(k \mid k)-\mathbf{T} \cdot f(k-1)-\mathbf{\Xi} \cdot \mathbf{A}(k)$ is the tracking error (difference between the future target, which in this case is zero, and the free response, $\left.\Delta \mathbf{F}_{d}(k)=\mathbf{0}\right)$. In order to guarantee the minimum solution the second derivative, or the Hessian matrix of $V(k)$, should be positive definite. This condition is verified if the weighting matrices are positive

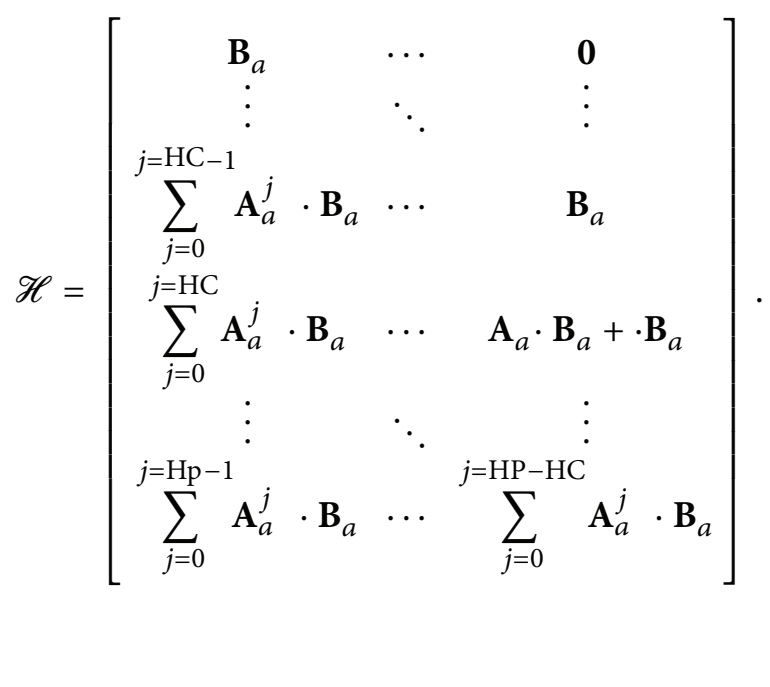

definite or at least one is positive definite and the other is semipositive definite.

If one cannot have access to the full state vector an observer has to be used to estimate the state vector $\widehat{\mathbf{z}}_{a}(k \mid k)$. The observer is designed using the Kalman filter technique: assuming that the plant is subjected to white noise disturbances (process noise $a_{g}(k)$ and measurement noise $v(k)$ ) with zero mean and known covariance matrices, $E\left[a_{g}(k)\right.$. $\left.a_{g}(k)^{T}\right]=Q_{o}, E\left[v(k) \cdot v(k)^{T}\right]=R_{o}$, then the observer gain $\mathbf{K}$ can be chosen to minimize the mean square state estimation error [25]. The observer equations include the time and measurement update and are given by

$$
\begin{gathered}
\widehat{\mathbf{z}}_{a}(k+1 \mid k)=\mathbf{A}_{a} \cdot \widehat{\mathbf{z}}_{a}(k \mid k)+\mathbf{B}_{a} \cdot f_{d}(k), \\
\widehat{\mathbf{y}}(k \mid k-1)=\mathbf{C}_{a} \cdot \widehat{\mathbf{z}}_{a}(k \mid k-1), \\
\widehat{\mathbf{z}}_{a}(k \mid k)=\widehat{\mathbf{z}}_{a}(k \mid k-1)+\mathbf{K} \cdot[y(k)-\widehat{y}(k \mid k-1)] .
\end{gathered}
$$

Manipulating the expressions of (9), the Kalman filter with a stationary gain is obtained by solving the corresponding Riccati equation with adequate covariance matrices:

$$
\begin{gathered}
\widehat{\mathbf{z}}_{a}(k+1 \mid k)=\mathbf{A}_{a}\left(\mathbf{I}-\mathbf{K} \cdot \mathbf{C}_{a}\right) \cdot \widehat{\mathbf{z}}_{a}(k \mid k-1) \\
+\mathbf{B}_{a} \cdot f_{d}(k)+\mathbf{A}_{a} \cdot \mathbf{K} \cdot \mathbf{y}(k), \\
\mathbf{K}=P_{o} \cdot \mathbf{C}_{a}^{T} \cdot\left[R_{o}+\mathbf{C}_{a} \cdot P_{o} \cdot \mathbf{C}_{a}^{T}\right]^{-1}, \\
P_{o}=\mathbf{E}_{a} \cdot Q_{o} \cdot \mathbf{E}_{a}^{T}+\mathbf{A}_{a} \cdot P_{o} \cdot \mathbf{A}_{a}^{T} \\
-\mathbf{A}_{a} \cdot P_{o} \cdot \mathbf{C}_{a}^{T}\left[R_{o}+\mathbf{C}_{a} \cdot P_{o} \cdot \mathbf{C}_{a}^{T}\right]^{-1} \cdot \mathbf{C}_{a} \cdot P_{o} \cdot \mathbf{A}_{a}^{T}
\end{gathered}
$$

In order to find adequate MPC controller solutions, stable closed-loop systems (linear counterpart, blocks SA device, and algorithm with unitary transfer functions) should be 
chosen. The closed-loop system equations can be found using the system's expressions (4), observer expressions (9), and the solution of the optimization problem (8). Only the first term of the $\Delta \mathbf{F}_{d}(k)$ will be used:

$$
\begin{array}{r}
\Delta f_{d}(k)=\mathbf{C}_{1} \cdot \widehat{\mathbf{z}}_{a}(k \mid k)+\mathbf{C}_{2} \cdot f_{d}(k-1)+\mathbf{C}_{3} \cdot a_{g}(k) \\
\text { with } \mathbf{C}_{1}=f r\left(-\mathbf{T}_{\text {term }} \cdot \Psi\right),
\end{array}
$$

$$
\begin{array}{r}
\mathbf{C}_{2}=\operatorname{fr}\left(-\mathbf{T}_{\text {term }} \cdot \mathbf{T}\right), \\
\mathbf{C}_{3}=\operatorname{fr}\left(-\mathbf{T}_{\text {term }} \cdot \boldsymbol{\Xi} \cdot \mathbf{1}\right), \\
\mathbf{T}_{\text {term }}=\left(\boldsymbol{\Theta}^{T} \cdot \mathcal{Q} \cdot \boldsymbol{\Theta}+\mathscr{R}\right)^{-1} \cdot \boldsymbol{\Theta}^{T} \cdot \mathcal{Q},
\end{array}
$$

where $\mathbf{1}$ is a unitary column vector and $\mathrm{fr}(\cdot)$ denotes the matrix first row. The closed-loop system is given by

$$
\begin{aligned}
{\left[\begin{array}{c}
\mathbf{z}_{a}(k+1) \\
\widehat{\mathbf{z}}_{a}(k+1 \mid k)
\end{array}\right]=} & {\left[\begin{array}{cc}
\mathbf{A}_{a}+\mathbf{B}_{a} \cdot\left(\mathbf{C}_{1} \cdot \mathbf{K} \cdot \mathbf{C}_{a}+\left(\mathbf{C}_{2}+1\right) \cdot \mathbf{M}_{01}\right) & \mathbf{B}_{a} \cdot \mathbf{C}_{1} \cdot\left(\mathbf{I}-\mathbf{K} \cdot \mathbf{C}_{a}\right) \\
\mathbf{A}_{a} \cdot \mathbf{K} \cdot \mathbf{C}_{a}+\mathbf{B}_{a} \cdot\left(\mathbf{C}_{1} \cdot \mathbf{K} \cdot \mathbf{C}_{a}+\left(\mathbf{C}_{2}+1\right) \cdot \mathbf{M}_{01}\right) & \left(\mathbf{A}_{a}+\mathbf{B}_{a} \cdot \mathbf{C}_{1}\right) \cdot\left(\mathbf{I}-\mathbf{K} \cdot \mathbf{C}_{a}\right)
\end{array}\right] } \\
& \cdot\left[\begin{array}{c}
\mathbf{z}_{a}(k) \\
\widehat{\mathbf{z}}_{a}(k \mid k-1)
\end{array}\right]+\left[\begin{array}{c}
\mathbf{E}_{a}+\mathbf{B}_{a} \cdot \mathbf{C}_{3} \\
\mathbf{B}_{a} \cdot \mathbf{C}_{3}
\end{array}\right] \cdot a_{g}(k),
\end{aligned}
$$

where $\mathbf{I}$ is the identity matrix and $\mathbf{M}_{01}$ is the matrix that satisfies $f_{d}(k-1)=\mathbf{M}_{01} \cdot \mathbf{z}_{a}(k)$. A stable system must have the dynamic matrix eigenvalues inside the unit circle. If all the states are available, the estimated state will be substituted by $\widehat{\mathbf{z}}_{a}(k \mid k)=\widehat{\mathbf{z}}_{a}(k \mid k-1)=\mathbf{z}_{a}(k)$ and the terms involving the observer gain $\mathbf{K}$ will cancel out in the above equations.

3.2. Control Algorithms. In the "SA Algorithm" block (see Figure 2) two different control algorithms were considered:

(1) variable damping (VD) is adequate for use with proportional valves since the damping can be changed continuously between the minimum and the maximum values; the inverse of the device's model (2) is used to convert the desired force $\left(f_{d}\right)$ into a damping value; to compute this value the algorithm also needs access to the relative velocity $\dot{x}_{r}$, the force derivative, and the device's physical limits $\left(c_{\min } \leq c_{v} \leq c_{\max }\right)$;

(2) the clipped on-off (COO) is the other control algorithm tested and this is a bang-bang control algorithm adequate for use with dampers employing onoff valves; this algorithm consists in applying the maximum damping when the device's force is smaller than the desired one and both have the same sign; otherwise the damping coefficient is set to the minimum value; this algorithm is implemented according to the following law $[6,8]$ :

$$
c_{v}=c_{\min }+\left(c_{\max }-c_{\min }\right) \cdot H\left[\left(f_{d}-f\right) \cdot f\right],
$$

where $H[\cdot]$ is the Heaviside step function. To implement this algorithm the devices force must be measured.

\section{Numerical Simulations}

4.1. Structural Systems. In this section a model of the structure subjected to typical Portuguese seismic actions will be used to test the effectiveness of the proposed control strategies. Only the acceleration (base floor acceleration for the MDOF system) will be used for feedback in the controller. Comparisons with the original structure (without any additional device), with the passive cases (the best one and the one with the maximum damping considered for the SA device), and with the semiactive case using and optimal controller will be presented. A nonlinear fluid viscous damper following the law $f_{P}=c_{p} \cdot \dot{x}_{r}^{\alpha}$ was considered for the best passive case. $f_{P}$ is the passive damper force, $c_{p}$ is the damping coefficient, $\dot{x}_{r}$ is the relative velocity, and $\alpha$ is the velocity exponent (it was found that $\alpha=0.15$ for the SDOF model and $\alpha=1$ for the MDOF model as the exponents that lead to the best passive cases performance). The best passive case is identified as the one having a damping coefficient that provides the lowest mean peak acceleration (top floor acceleration for the MDOF model). Figure 3 shows the typical plot of the evolution of the responses with the device damping values (a) and the identified damping values for type 1 and type 2 seismic actions corresponding to the best passive cases (b).

A semiactive solution employing an optimal controller (stochastic linear quadratic regulator [6]) with a unitary input weight and an output weight on the base acceleration that minimizes the mean peak acceleration for each set of seismic actions [16] (referred as SALQRVD) was also considered for comparison. Relative displacement and absolute accelerations will be considered to evaluate the systems' performance.

At first a SDOF system is used to model the first vibration mode of base-isolated structures (building supported by bearings) considering that the base isolation system is flexible and the superstructure (building structure) is rigid enough as to be modelled as a rigid mass (base mass plus superstructure's mass). Base isolation systems are used to reduce the structure's natural frequency and deviate it from the seismic input action frequency content. Common base isolation systems are designed to have natural frequencies bellow $1 \mathrm{~Hz}$. In order to evaluate the performance of several base isolation systems the model's properties considered in 


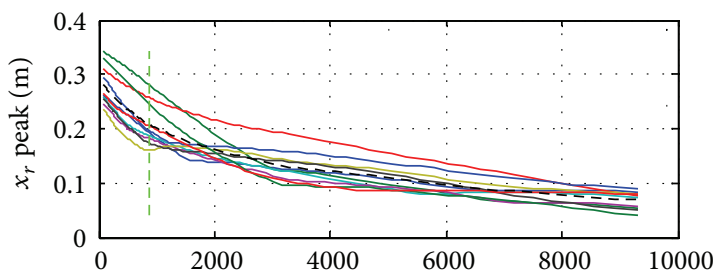

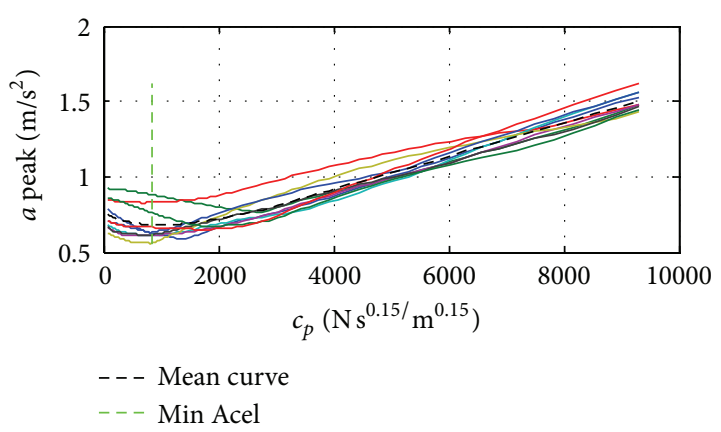

(a)

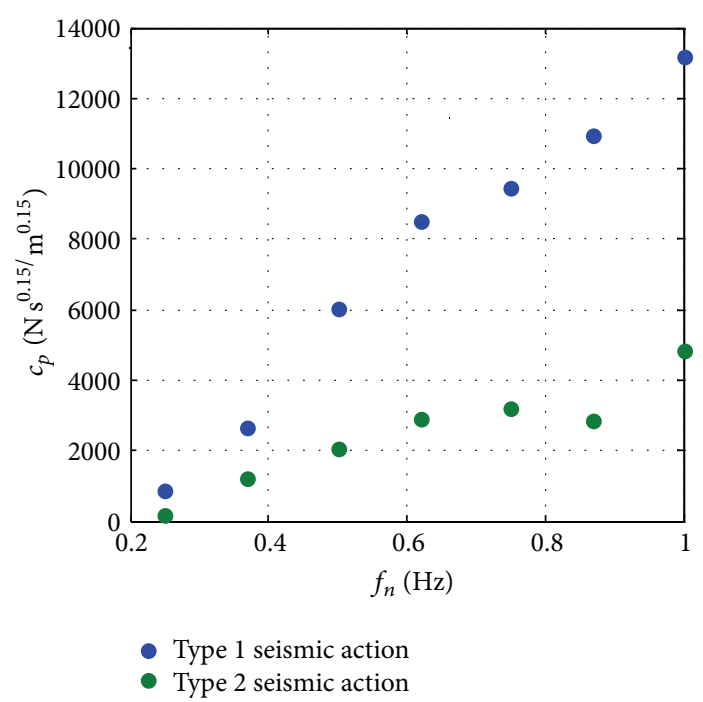

(b)

FIGURE 3: Simulation results for the SDOF model $\left(f_{n}=0.25 \mathrm{~Hz} ; \xi=10 \%\right)$ with a passive damper. (a) Evolution of responses versus passive device damping for 10 type 1 seismic actions and the correspondent mean curve; (b) damping coefficients (for $\alpha=0.15$ ) for the minimum mean peak acceleration response function of system natural frequencies under type 1 and 2 seismic actions.
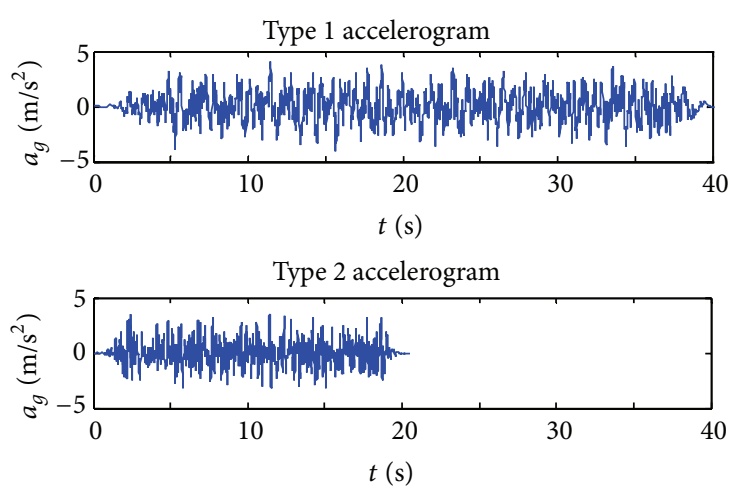

(a)
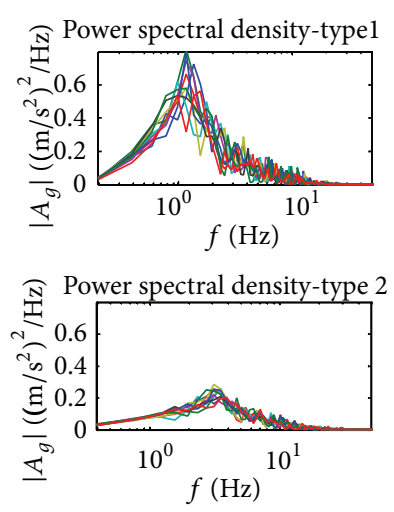

(b)

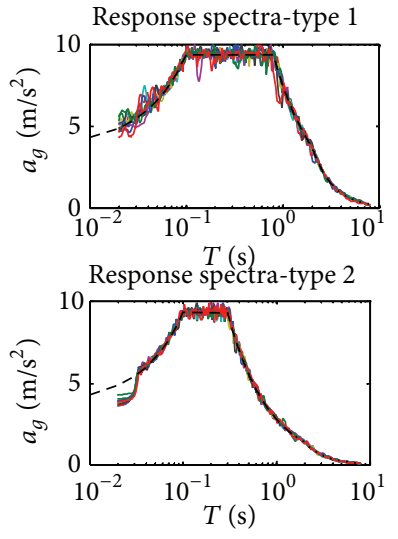

(c)

FIGURE 4: Input ground motions characteristic considered in the numerical simulations. (a) One of ten artificial accelerograms; (b) frequency spectra of 10 accelerograms; (c) response spectra of 10 accelerograms.

the simulations were $m=5750 \mathrm{~kg}$ (mass), $f_{n}=0.25$ to $1 \mathrm{~Hz}$ (natural frequency), and $\xi=0.1$ (damping ratio). The semiactive fluid damper can add additional damping between $\xi_{\min }=0.05$ and $\xi_{\max }=(1-\xi) / 2=0.45$. The device's dynamics is characterized by a time constant of $T_{d}=0.05 \mathrm{~s}$ which is an average of time delays found in $[15,17]$. Two different semiactive control strategies were considered depending on the algorithm used, although both make use of the predictive controller: (i) SAMPCVD, for a variable damping algorithm; (ii) SAMPCCOO, when a clipped on-off algorithm is used. In the end, a 10-storey base-isolated building (MDOF model) is used to verify the effectiveness of the proposed strategies.

4.2. Input Action. The input actions considered in this work were artificial accelerograms generated using the extreme response spectrums provided in the Eurocode 8 for Portugal
[26]: type 1 (far field) seismic action; type 2 (near field) seismic action. Ten accelerograms were generated for each spectrum. The accelerograms were generated for zone 1, soil type D, and structures of class II importance. The accelerograms and the spectrums are presented in Figure 4. It can be seen that type 1 input action has a longer duration, is richer in the lower frequencies (or higher periods), and has higher amplitudes. It must be referred that if other specifications were used, for example, ASCE 7 [27], the seismic hazard would be described in a different way, especially for near-fault applications.

4.3. SDOF Model Results. Numerical simulations were performed in the time domain considering the generated artificial accelerograms as inputs. MATLAB/Simulink environment was used to run the simulations. 

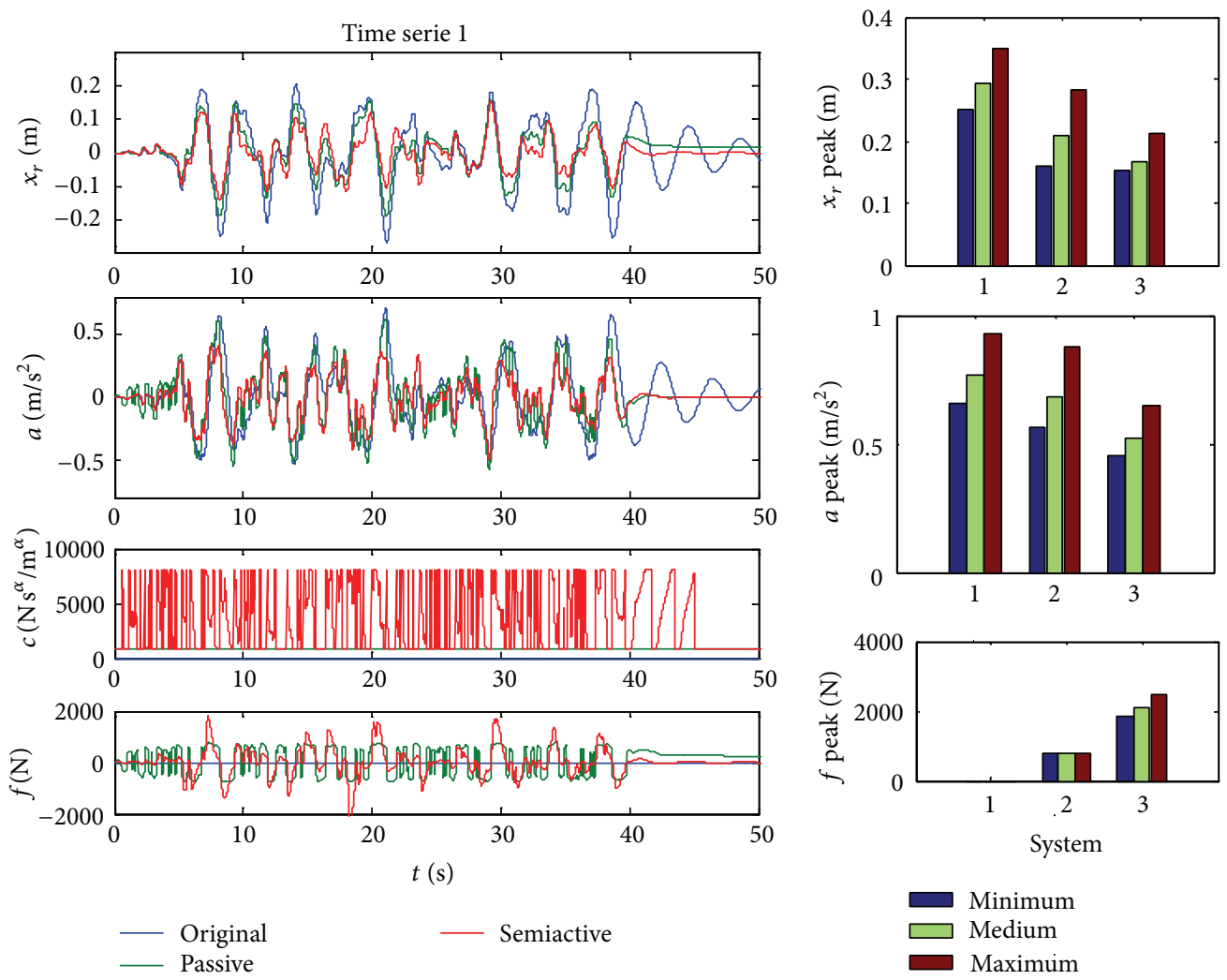

(a)

(b)

FIGURE 5: (a) Simulation results for the SDOF model $\left(f_{n}=0.25 \mathrm{~Hz}\right.$ and $\left.\xi=10 \%\right)$ subjected to one type 1 accelerogram without devices, with passive and SAMPCVD; (b) peak values' statistics for 10 type 1 input time series.

The predictive controller described has several adjustable parameters: weights (acceleration weight $Q$ and input move weight $R$ ), horizons ( $\mathrm{HP}$ and $\mathrm{HC}$ ), control interval $\left(T_{s}\right)$, and observer dynamics (covariance matrices $Q_{0}$ and $R_{0}$ ). The weights and covariance matrices are $1 \times 1$ dimension matrices since the controller's internal model is characterized by one input (desired force) and one output (acceleration); thus, $Q=$ $q, R=r, Q_{0}=q_{0}$, and $R_{0}=r_{0}$. For nonlinear problems tuning these parameters is a question of applying a set of "rules of thumb" based on experience gained from simulations [24]. Following the methodology that will be described below, adequate parameters for this kind of problems were found. It will be shown that a well-tuned controller could improve the system's performance (relative displacement and absolute acceleration) even better than the best passive solution, only by changing the damping coefficient in "real time." Typical system's responses are shown in Figure 5.

The control interval (or sampling period) should be adequate to capture the system's dynamics. Its value is delimited by the time taken to solve the optimization problem and by the inverse of the Nyquist frequency, obtained from the smallest time constant of the system. It should also be small enough so that the control input (desired force or damping) responds quickly to the output changes. In contrast, the limit is the passive case where damping is constant. An example of the influence of this parameter on the system's performance (mean peak responses) can be found in Figure 6 where a comparison with different values of control interval and prediction horizons is presented for the SDOF case. It is shown that higher control intervals lead to poor performances (increases in relative displacements and absolute accelerations). Higher control intervals also have a negative impact on the evolution of responses with the prediction horizon. As the control interval increases the range of prediction horizons that lead to good performances gets smaller (see Figure 6(a)), and thus as the control interval increases smaller prediction horizons should be considered to achieve good responses. A control interval (or sampling time) of $T_{s}=5 \mathrm{~ms}$ was considered in this work.

The observer was designed with a Kalman filter with unitary covariance matrices. This solution is a compromise between observer response in estimating the state vector and control aggressiveness. A deadbeat observer would be preferable but it could lead to aggressive control actions which would compromise the overall performance of the system.

In order to identify the range of acceptable controllers the closed-loop linear system counterpart was analysed. The maximum moduli of the eigenvalues for the closed-loop system were used to identify the systems' stability: stable systems have their eigenvalues inside the unit circle and thus their moduli are less than one. Time delays $d$ were considered on the simulations to compensate for the device dynamics $T_{d}$ 

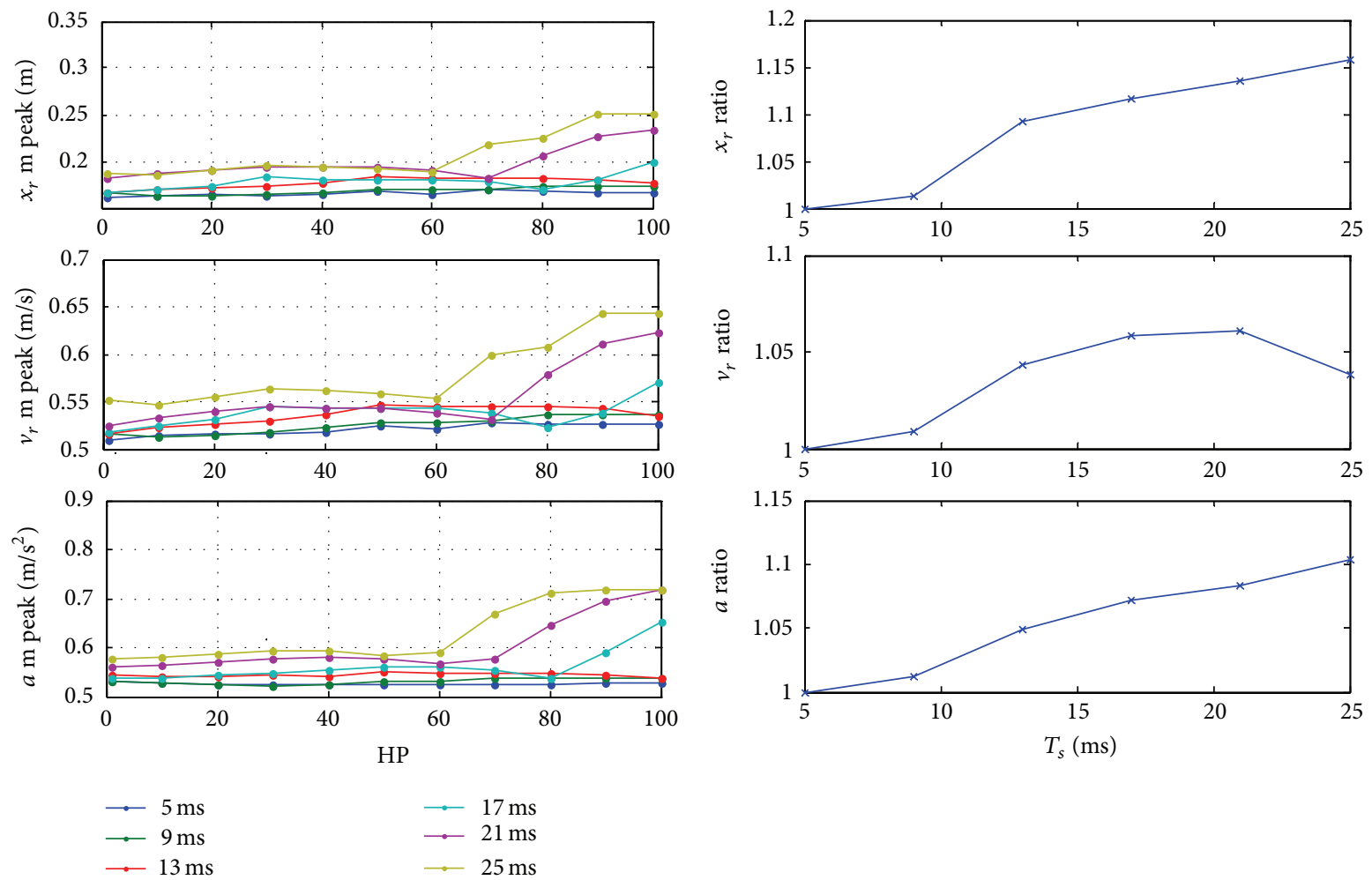

(a)

(b)

FiguRE 6: (a) SDOF system's mean peak responses $\left(f_{n}=0.25 \mathrm{~Hz}\right.$ and $\xi=10 \%$ for SAMPCVD with HC $=1$ and $\left.r=1\right)$ evolutions with control interval $T_{s}$ and prediction horizon HP, when subjected to type 1 seismic actions (10 accelerograms). (b) Ratios evolution with control interval (relative to $T_{s}=5 \mathrm{~ms}$ ) for $\mathrm{HP}=50$.

(time response). Figure 7(a) shows an example of the maximum moduli evolution with the acceleration weight $q$. It can be seen that the desired solution lies in the range $q^{0.5}<150$. After that, each structural system with an SA device was subjected to 10 accelerograms of each action type and the mean peak values were evaluated. Applying this procedure for different weights and horizons, combinations of these parameters that lead to the best system's response were found. Figure 7(b) shows the evolution of system's peak responses with the controller acceleration weight $q$ for each accelerogram (with $r=1$ ). The dashed vertical line indicates the minimum of the mean peak acceleration curve. Using this point as criteria to design the controller, reductions in relative displacement and velocity are also achieved, which leads also to reductions in base shear forces. Higher values for this weighting parameter lead to poor performances in terms of relative displacement and acceleration. In fact, for higher acceleration weights the closed-loop system becomes unstable as mentioned before, and the desired force resulting from the controller goes to infinity which leads to poor performance.

It was also found that an increase on the input move weight $r$ slides those curves (responses versus acceleration weight) to the right, meaning that the acceleration weight that minimizes the acceleration response also increases. From the analysis of the cost function (7) increasing the input move weight relative to the output weights has the effect of reducing the control activity. In the present study a unitary weight in the input move was considered.

The results with different prediction and control horizons showed similar responses although for higher prediction horizons higher responses are obtained. Figure 7(c) shows the typical evolution of the responses (mean peak values) with this parameter. An almost constant evolution of relative displacements and absolute accelerations were found with the prediction horizon HP up to a value dependent on the system's natural frequency and control interval $(\mathrm{HP}=70$ for $f_{n}=1 \mathrm{~Hz}$ and $T_{s}=5 \mathrm{~ms}$, and higher values of $\mathrm{HP}$ for lower natural frequencies). Above those values the responses increase (poor performances). Thus, prediction horizons inferior to 70 were found to be adequate for the studied cases. In fact, having found no significant influence of the prediction horizon on the results in that range, the smallest value is desired in order to reduce the order of the controller (matrices dimension, solution of the optimization problem). However, since the internal model has input delays to account for the device's response, one should assure that $\mathrm{HP}>d$. In the present study the instant delays are $d=10(50 \mathrm{~ms})$ and thus the prediction horizon was set to $\mathrm{HP}=50$. In what concerns the influence of the control horizon $\mathrm{HC}$ in the results, no evidence of improvements was found for $\mathrm{HC}>1$, 


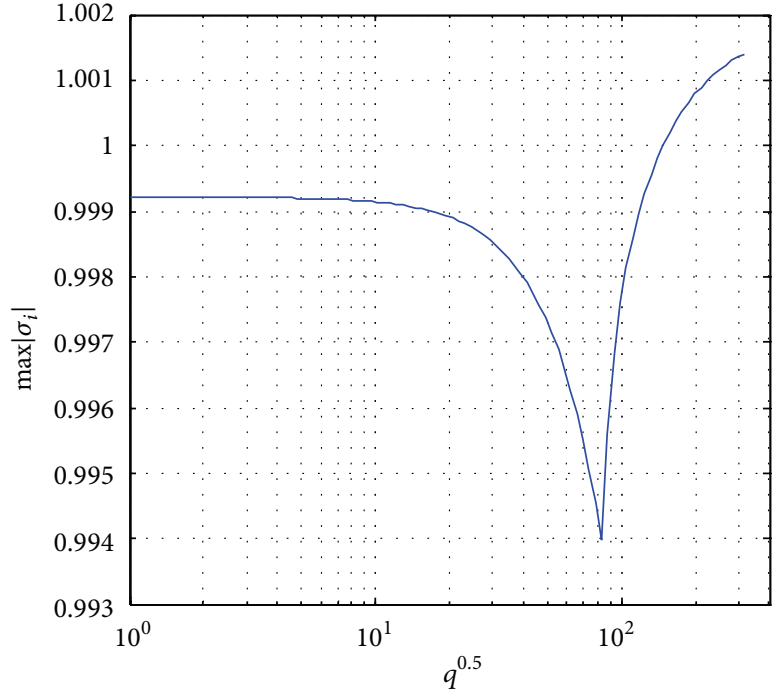

(a)
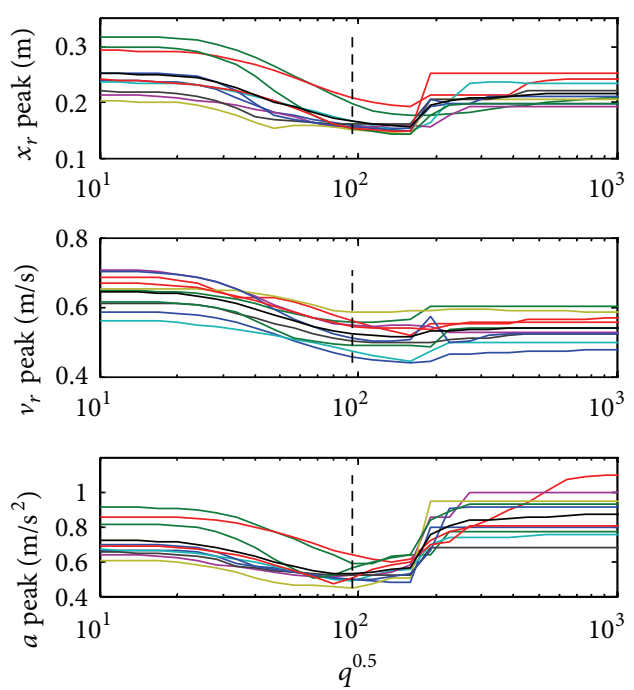

(b)
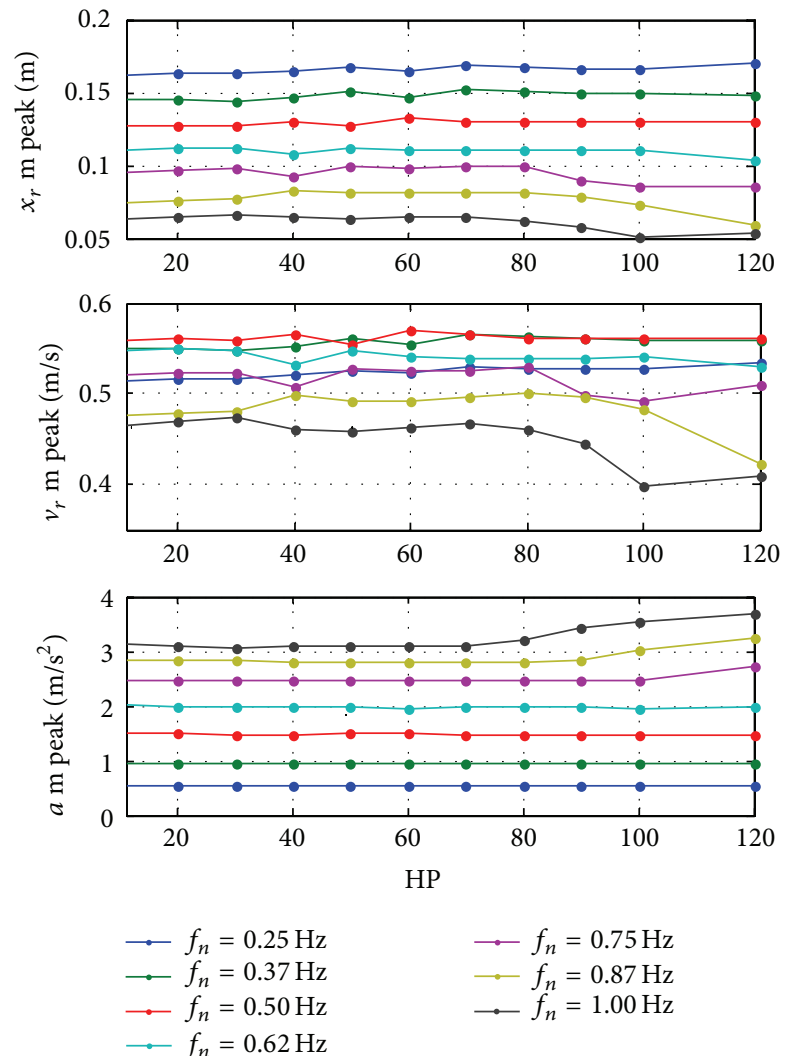

(c)

FIGURE 7: Result for system with $f_{n}=0.25 \mathrm{~Hz}$ and $\xi=10 \%$ considering $T_{s}=5 \mathrm{~ms}, \mathrm{HC}=1 . r=1$ and $d=10$. (a) System eigenvalues' moduli (maximum values) evolution with acceleration weight; (b) system responses' (peak values) evolution with acceleration weight when subjected to type 1 seismic actions; (c) system responses' (mean peak values) evolution with prediction horizon for different natural frequencies $\left(f_{n}=\right.$ 0.25 to $1.00 \mathrm{~Hz}$ ) for SAMPCVD, when subjected to type 1 seismic actions (10 input time accelerograms).

and thus the unitary value was considered in the subsequent analysis.

Good performance is achieved with the parameterization previously indicated since the device force follows very closely the desired force, as is shown in Figure 8.
Having found the best parameters, the mean peak responses for each structural system (with different natural frequencies) were determined. Comparisons with the original, passive (with a damping coefficient for the lowest mean peak top floor acceleration), and semiactive with an optimal 

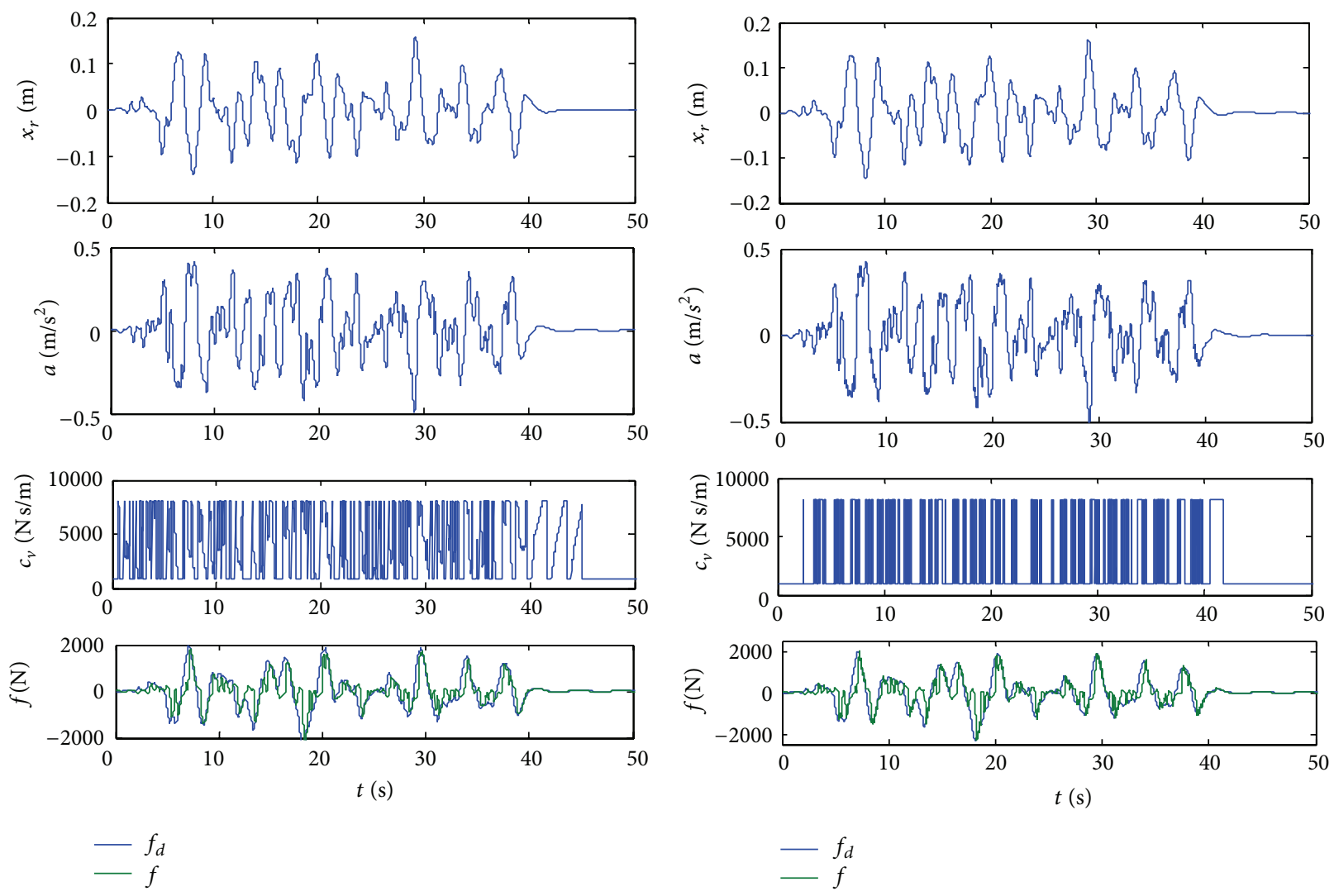

(a)

(b)

FIGURE 8: Simulation results for the SDOF model $\left(f_{n}=0.25 \mathrm{~Hz}\right.$ and $\left.\xi=10 \%\right)$ subjected to one type 1 accelerogram employing SA systems with $T_{s}=5 \mathrm{~ms}, \mathrm{HP}=50, \mathrm{HC}=1, r=1$, and $d=10$, with both VD (a) and COO (b) control algorithms.

controller are presented in Figure 9. It is shown that any proposed system is better than the original one. In terms of accelerations the proposed semiactive systems show the best performance for structural systems with natural frequencies below $0.6 \mathrm{~Hz}$ for type 1 seismic actions, and below $1 \mathrm{~Hz}$ for type 2 seismic actions. This means that base isolation systems should employ semiactive devices in detriment of passive ones on such circumstances. It can also be seen that the SA device controlled by an on-off algorithm almost reaches the same performance of the variable damping algorithm. This result shows that a simple solenoid valve can be used instead of a proportional one, which in terms of practical implementation leads to a less expensive solution. It was also found that the proposed solution with an MPC controller is slightly better than the one with an optimal controller in terms of both relative displacements and accelerations. Thus, the SA systems presented can provide reductions in relative displacements (between 50 and $60 \%$ ) when compared to the original structure, improve the acceleration responses better than the best passive case, and outperform the SA one with an optimal controller.

Other numerical simulations were performed with structural systems of different properties $(m, k$, and $c)$. The main difference found was on the optimal acceleration weight $q$. Thus, for different structural systems this value should be determined (with the proposed values for the other parameters) under a numerical analysis by finding first a range of stable solutions and then considering a representative set of accelerograms of the site where the structure is to be installed to find the weight $q$ that leads to the best performance.

4.4. MDOF Model Results. A ten-storey base-isolated structure was considered to evaluate the effectiveness of the presented strategies. The superstructure's fundamental frequency is $f_{s 1}=1.6 \mathrm{~Hz}$ (representative of a 10-storey dual frame-wall structure), and a damping ratio of $\xi_{1}=5 \%$ is assumed. Each floor has a mass of $m_{f}=10^{5} \mathrm{~kg}$. The stiffness and damping matrices were determined considering constant stiffness between floors and a stiffness proportional damping matrix $\left(\mathbf{C}=a_{0} \cdot \mathbf{K}\right)$, which correspond to stiffness and damping coefficients between floors of $k_{f}=452.43 \mathrm{kN} / \mathrm{mm}$ and $c_{f}=1.51 \mathrm{kN} \mathrm{s} / \mathrm{mm}$ with $a_{0}=0.0033 \mathrm{~s}$. The superstructure is supported on a base isolation system with mass $m_{i}=1.4$. $m_{f}$ and laminated rubber bearings made of natural rubber represented by a linear elastic and viscous model, with a target frequency $f_{i}=0.4 \mathrm{~Hz}$ and an equivalent damping ratio of $\xi_{i}=10 \%$. The correspondent stiffness and damping coefficients were obtained assuming a rigid superstructure: $k_{i}=$ $7.20 \mathrm{kN} / \mathrm{mm}$ and $c_{i}=0.57 \mathrm{kN} \mathrm{s} / \mathrm{mm}$. The base-isolated structure model is obtained after assembling the base isolation 


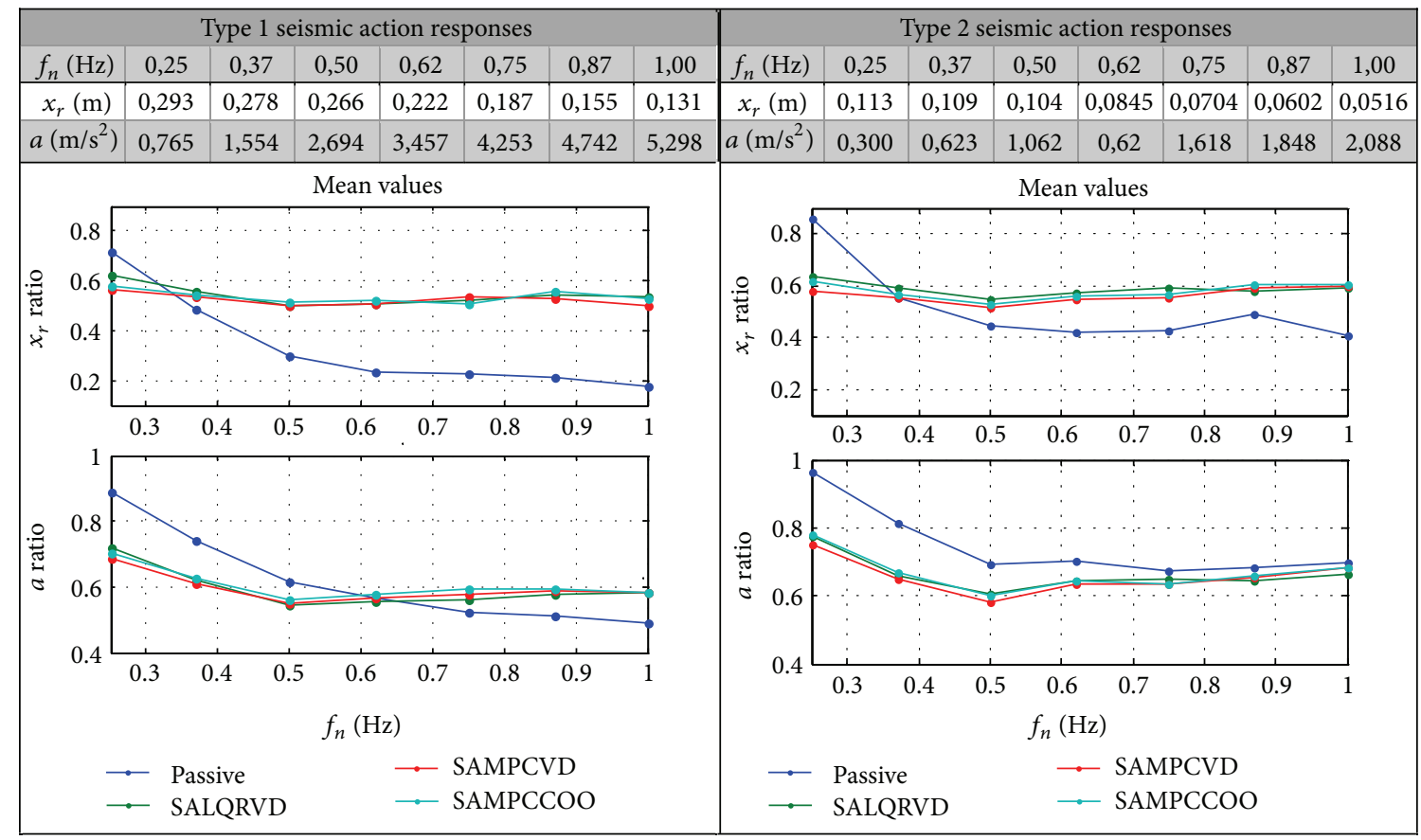

FIGURE 9: SDOF mean peak response values for the original system and ratios (relative to the original structure) for different system's natural frequencies.
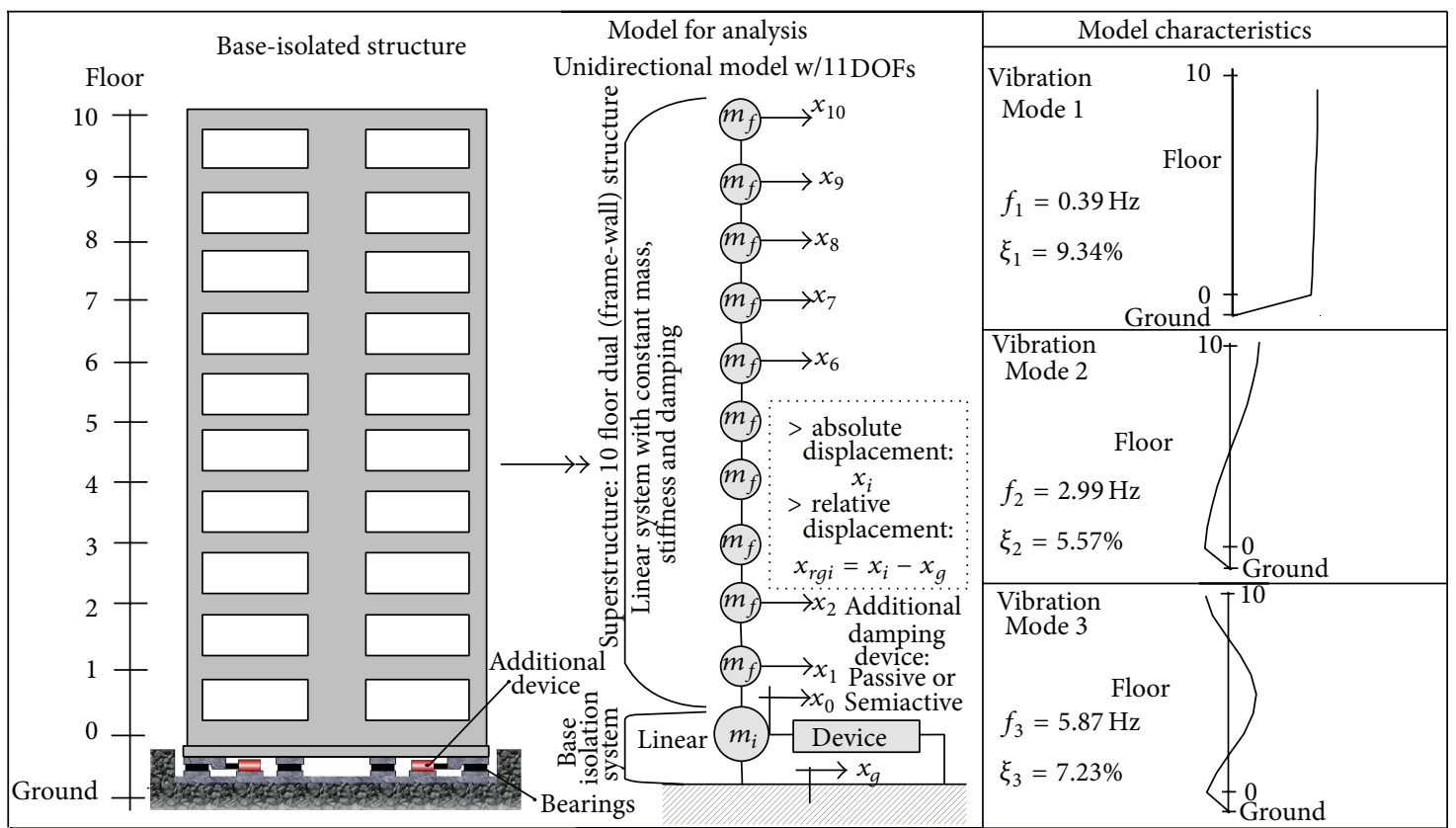

FIGURE 10: 10-storey base-isolated building and equivalent model for analysis.

system and the superstructure models together. Figure 10 depicts the model under study. Considering the controller parameters for the SDOF case, the MPC scheme was implemented assuming a rigid superstructure and thus only the base acceleration is used for feedback. After analysing the closed-loop system the acceleration weight $q^{0.5}=10^{4}$ was chosen. Figure 11 and Table 1 show a comparison of results with the original structure, the best passive (with a damping coefficient for the lowest mean peak top floor acceleration, $c_{\mathrm{id}}=1.1 \mathrm{kN} \mathrm{s} / \mathrm{mm}$, additional damping of $\xi=$ $0.19)$ case, the passive with maximum damping, $c_{\max }=$ $2.58 \mathrm{kN} \mathrm{s} / \mathrm{mm}$ (additional damping of $\xi=0.45$ ), and with the semi-active manipulated by an optimal controller (controller implemented considering a rigid superstructure 
TABLE 1: 10-storey base isolated building results. Comparison in terms of mean response peak values ratios: relative displacements, accelerations (at base and top) and base shear force $V$, in relation to the original structure; and peak device's force ratio $f / W$ in relation to the structure's weight $W$.

\begin{tabular}{lcccccccccccc}
\hline \multirow{2}{*}{ System } & \multicolumn{9}{c}{ Type 1 seismic action } & \multicolumn{4}{c}{ Type 2 seismic action } \\
& $x_{r \text { base }}$ & $x_{r \text { top }}$ & $a_{\text {base }}$ & $a_{\text {top }}$ & $V$ & $f / W$ & $x_{r \text { base }}$ & $x_{r \text { top }}$ & $a_{\text {base }}$ & $a_{\text {top }}$ & $V$ & $f / W$ \\
\hline Passive $c_{\text {id }}$ & 0.67 & 0.67 & 0.87 & 0.88 & 0.77 & 0.04 & 0.70 & 0.71 & $\mathbf{1 . 1 4}$ & $\mathbf{1 . 0 9}$ & 0.82 & 0.02 \\
Passive $c_{\text {max }}$ & 0.40 & 0.41 & $\mathbf{1 . 0 3}$ & $\mathbf{1 . 1 4}$ & 0.78 & 0.10 & 0.42 & 0.44 & $\mathbf{1 . 6 4}$ & $\mathbf{1 . 6 3}$ & 0.93 & 0.05 \\
SALQRVD & 0.60 & 0.60 & 0.83 & 0.85 & 0.70 & 0.05 & 0.64 & 0.64 & $\mathbf{1 . 0 7}$ & $\mathbf{1 . 0 7}$ & 0.75 & 0.02 \\
SAMPCVD & 0.65 & 0.66 & 0.77 & 0.78 & 0.70 & 0.04 & 0.69 & 0.70 & 0.91 & 0.89 & 0.75 & 0.02 \\
SAMPCCOO & 0.66 & 0.66 & 0.81 & 0.81 & 0.71 & 0.04 & 0.69 & 0.70 & 0.98 & 0.93 & 0.75 & 0.02 \\
\hline
\end{tabular}
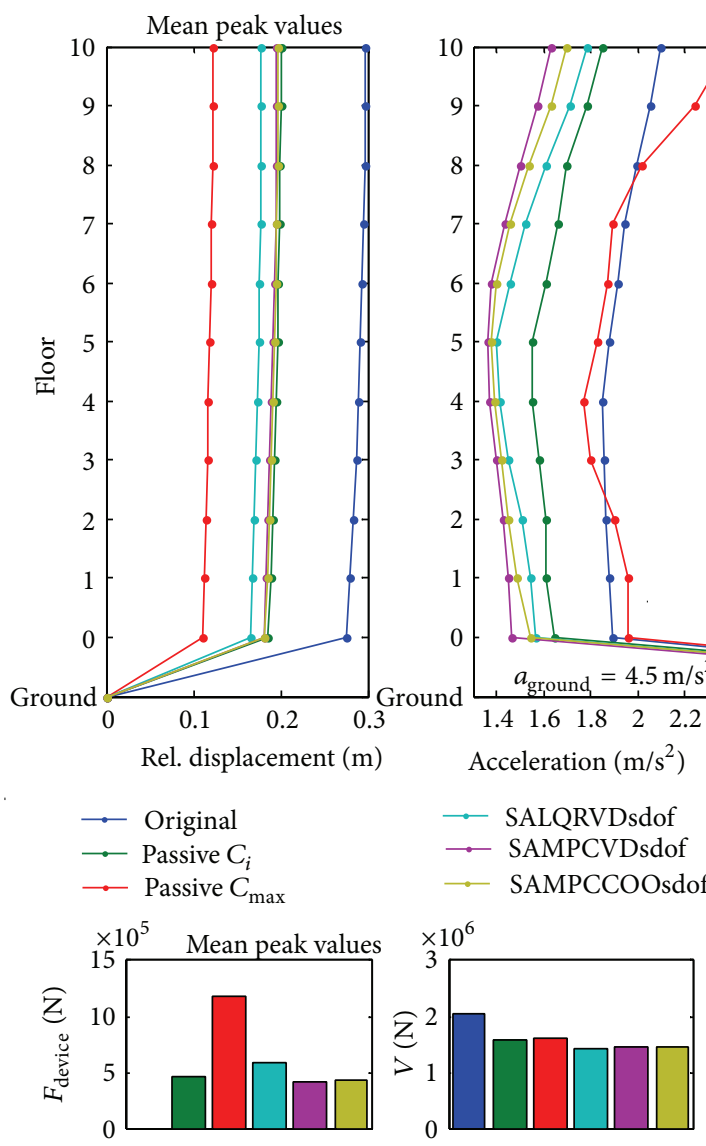
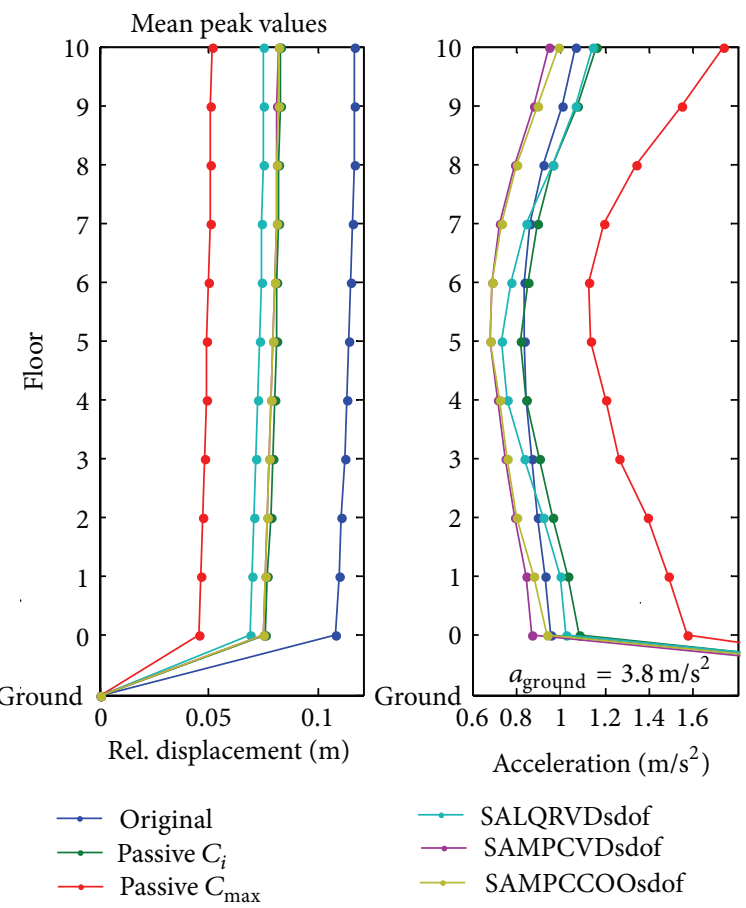

$\longrightarrow$ SALQRVDsdof

$\rightarrow$ SAMPCVDsdof

$\ldots$ SAMPCCOOsdof

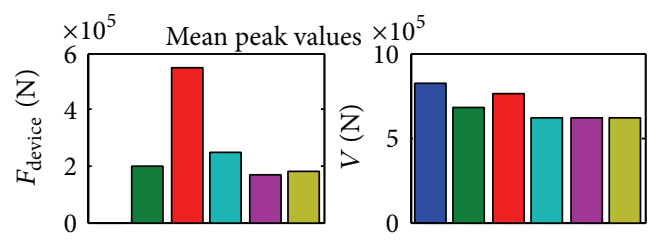

FIGURE 11: 10-storey base-isolated building responses to 10 type 1 and type 2 accelerograms. Mean peak values in terms of relative displacements, accelerations, base shear $V$, and device's force $f$ for the systems under study.

with weighting values determined as for de SDOF case; see Section 4.1).

The results show that all solutions can improve the structure's relative displacements, with the maximum damping passive device having the best performance for this parameter. However, this solution has the disadvantage of increasing the acceleration responses, especially for type 2 seismic actions, with higher damper forces. The SA solutions appear as an attractive answer to the problem since it is possible to reduce the base relative displacements without compromising and even improving the acceleration responses. The proposed solutions perform also better in terms of acceleration than the one considering an optimal controller to manipulate the SA device. However, the last one has the disadvantage of slightly increasing the accelerations more than the original structure for type 2 seismic actions. In terms of displacement at the base level, the optimal controller solution performs better than the MPC-based ones. Even the best passive solution (passive $c_{\text {id }}$ ) has the inferior performance in terms of absolute accelerations. All the solutions can reduce the base shear forces transmitted to the structure at the base since part of the seismic force is dissipated by the devices. Thus, higher damper forces lead to lower base relative displacements. It is shown also that SA device control forces (mean peak values) are less than $5 \%$ of the structure's weight. The results also show that an SA device manipulated by an on-off algorithm (COO) 
can achieve similar results to that of a variable damping algorithm (VD). Differences are less than $1 \%$ in terms of relative displacements but major differences are found in the accelerations, which can reach $7 \%$ for the base floor acceleration when type 2 seismic actions are considered.

\section{Conclusions}

A force tracking scheme comprising a predictive controller and a semiactive control algorithm is proposed for damping control of semiactive fluid dampers employed in base isolation systems subjected to earthquake loads. The controller formulation includes the input delays resulting from the device's behaviour. Moreover, assuming that all the system's variables are not always available, the controller was formulated using an embedded observer as well. The numerical simulations show that a well-tuned controller can improve the system's performance (peak of relative displacement and absolute acceleration) only by changing the damping in "real time." The proposed solution outperforms the original structure and the structural system with passive devices for natural frequencies below $0.6 \mathrm{~Hz}$ when subjected to several artificial accelerograms generated according to current codes for the Portuguese territory. The parametric study of a SDOF model provided some indicators to tune the controller. However, with the proposed tuning the acceleration weight always has to be determined by numerical simulations of the closed-loop system under several input accelerograms. Slightly better performance was found with the proposed strategy when compared with the solution provided by an optimal controller to manipulate the SA device. When applied to a MDOF system, a 10-storey base-isolated structure, better performance than the original and passive cases, was also found in terms of accelerations. The proposed solution also outperforms the SA solution manipulated by an optimal controller in terms of accelerations. In terms of relative displacements, the passive case with maximum damper and the SA device manipulated by an optimal controller provide better results but at the expense of increasing the absolute accelerations.

It has been demonstrated that a predictive controller with an adjusting damping rule can be effective in reducing earthquake induced responses using variable fluid dampers. The range of controller acceleration weights is first determined by the analysis of the closed-loop system and tuned through numerical simulations using a representative number of accelerograms (test functions) from the site of structures' installation. Thus, the proposed strategies have potential for future implementations in civil engineering structures located in active seismic zones.

\section{Conflict of Interests}

The authors declare that there is no conflict of interests regarding the publication of this paper.

\section{Acknowledgments}

The authors would like to thank the Portuguese Foundation for Science and Technology (FCT) for the Ph.D. scholarship provided (reference SFRH/BD/84769/2012) and to LNEC and IST for providing the resources needed to develop this work.

\section{References}

[1] T. T. Soong and G. F. Dargush, Passive Energy Dissipation Systems in Structural Engineering, John Wiley \& Sons, New York, NY, USA, 1997.

[2] A. K. Chopra, Dynamics of Structures: Theory and Applications to Earthquake Engineering, Prentice Hall, New York, NY, USA, 2nd edition, 1995.

[3] J. M. Kelly, "The role of damping in seismic isolation," Earthquake Engineering and Structural Dynamics, vol. 28, no. 1, pp. 3-20, 1999.

[4] T. T. Soong and B. F. Spencer Jr., "Supplemental energy dissipation: state-of-the-art and state-of-the-practice," Engineering Structures, vol. 24, no. 3, pp. 243-259, 2002.

[5] M. D. Symans and M. C. Constantinou, "Semi-active control systems for seismic protection of structures: a state-of-the-art review," Engineering Structures, vol. 21, no. 6, pp. 469-487, 1999.

[6] A. Preumont, Vibration Control of Active Structures-An Introduction, Kluwer Academic, New York, NY, USA, 2nd edition, 2002.

[7] Y. Ikeda, "Active and semi-active vibration control of buildings in Japan-practical applications and verification," Structural Control and Health Monitoring, vol. 16, no. 7-8, pp. 703-723, 2009.

[8] S. J. Dyke and B. F. Spencer Jr., "A comparison of semi-active control strategies for the MR damper," in Proceedings of the International Conference on Intelligent Information Systems (IIS '97), pp. 580-584, Grand Bahama Island, Bahamas, December 1997.

[9] D. Shook, P. Lin, T. Lin, and P. N. Roschke, "A comparative study in the semi-active control of isolated structures," Smart Materials and Structures, vol. 16, no. 4, pp. 1433-1446, 2007.

[10] N. Aguirre, F. Ikhouane, and J. Rodellar, "Proportional-plusintegral semiactive control using magnetorheological dampers," Journal of Sound and Vibration, vol. 330, no. 10, pp. 2185-2200, 2011.

[11] A. Rodríguez, F. Pozo, A. Bahar, L. Acho, Y. Vidal, and J. Rodellar, "Force-derivative feedback semi-active control of baseisolated buildings using large-scale MR fluid dampers," Structural Control and Health Monitoring, vol. 19, no. 1, pp. 120-145, 2012.

[12] M. Zapateiro, H. R. Karimi, N. Luo, and B. F. Spencer Jr., "Realtime hybrid testing of semiactive control strategies for vibration reduction in a structure with MR damper," Structural Control and Health Monitoring, vol. 17, no. 4, pp. 427-451, 2010.

[13] A. M. Aly, A. Zasso, and F. Resta, "On the dynamics of a very slender building under winds: response reduction using MR dampers with lever mechanism," Structural Design of Tall and Special Buildings, vol. 20, no. 5, pp. 539-551, 2011.

[14] A. M. Aly, "Vibration control of buildings using magnetorheological damper: a new control algorithm," Journal of Engineering, vol. 2013, Article ID 596078, 10 pages, 2013.

[15] M. D. Symans and M. C. Constantinou, "Development and experimental study of semi-active fluid damping devices for seismic protection of structures," Report No. NCEER 95-0011, National Center for Earthquake Engineering Research, Buffalo, NY, USA, 1995.

[16] F. Sadek and B. Mohraz, "Semiactive control algorithms for structures with variable dampers," Journal of Engineering Mechanics, vol. 124, no. 9, pp. 981-990, 1998. 
[17] I. Nagashima, Y. Shinozaki, R. Maseki et al., "A building with semi-active base isolation using sliding mode control," in Proceedings of the World Forum on Smart Materials and Smart Structures Technology (SMSST '07), pp. 523-524, May 2007.

[18] H. Kurino, J. Tagami, K. Shimizu, and T. Kobori, "Switching oil damper with built-in controller for structural control," Journal of Structural Engineering, vol. 129, no. 7, pp. 895-904, 2003.

[19] H. Kurino, Y. Matsunaga, T. Yamada, and J. Tagami, "High performance hydraulic damper with semi-active characteristics," in Proceedings of the 13th World Conference on Earthquake Engineering, paper no. 33, p. 12, Vancouver, Canada, August 2004.

[20] H. Kurino, S. Orui, and K. Shimizu, "Structural control by innovative oil damper with automatic on/off valve operation," Journal of Disaster Research, vol. 4, no. 3, pp. 253-260, 2009.

[21] A. Occhiuzzi and G. Serino, "A semi-active oleodynamic damper for earthquake control-part 2: evaluation of performance through shaking table tests," Bulletin of Earthquake Engineering, vol. 1, no. 2, pp. 241-273, 2003.

[22] J. F. Hall, "Discussion: the role of damping in seismic isolation," Earthquake Engineering and Structural Dynamics, vol. 28, no. 12, pp. 1717-1720, 1999.

[23] E. D. Wolff and M. C. Constantinou, "Experimental study of seismic isolation systems with emphasis on secondary system response and verification of accuracy of dynamic response history analysis methods," Report No. MCEER-04-0001, Multidisciplinary Center for Earthquake Engineering Research, Buffalo, NY, USA, 2004.

[24] J. M. Maciejowski, Predictive Control with Constraints, Pearson Education, Upper Saddle River, NJ, USA, 2002.

[25] F. L. Lewis, Optimal Estimation: With an Introduction to Stochastic Control Theory, John Wiley \& Sons, New York, NY, USA, 1986.

[26] EN, 1998-1, "Eurocode 8-1: design of structures for earthquake resistance," Portuguese Version: Eurocodigo8, Projecto de Estruturas para Resistência aos Sismos-Parte 1: Regras Gerais, Acções Símicas e Regras para Edifícios, Instituto Português da Qualidade, NP EN, 1998-1, 2010, http://eurocodes.jrc.ec.europa .eu/showpage.php?id=138.

[27] ASCE/SEI 7, "Minimum design loads for buildings and other structures," ASCE Standard, American Society of Civil Engineers, 2010, http://www.asce.org/sei/Content.aspx?id= 23622324319 . 

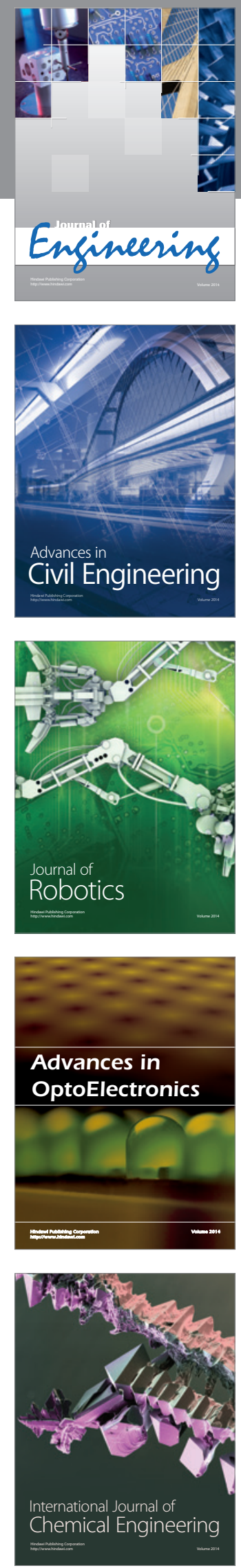

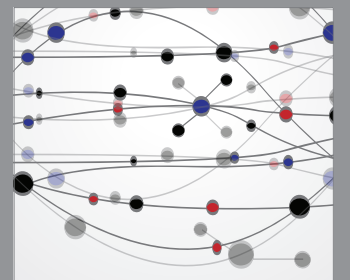

The Scientific World Journal
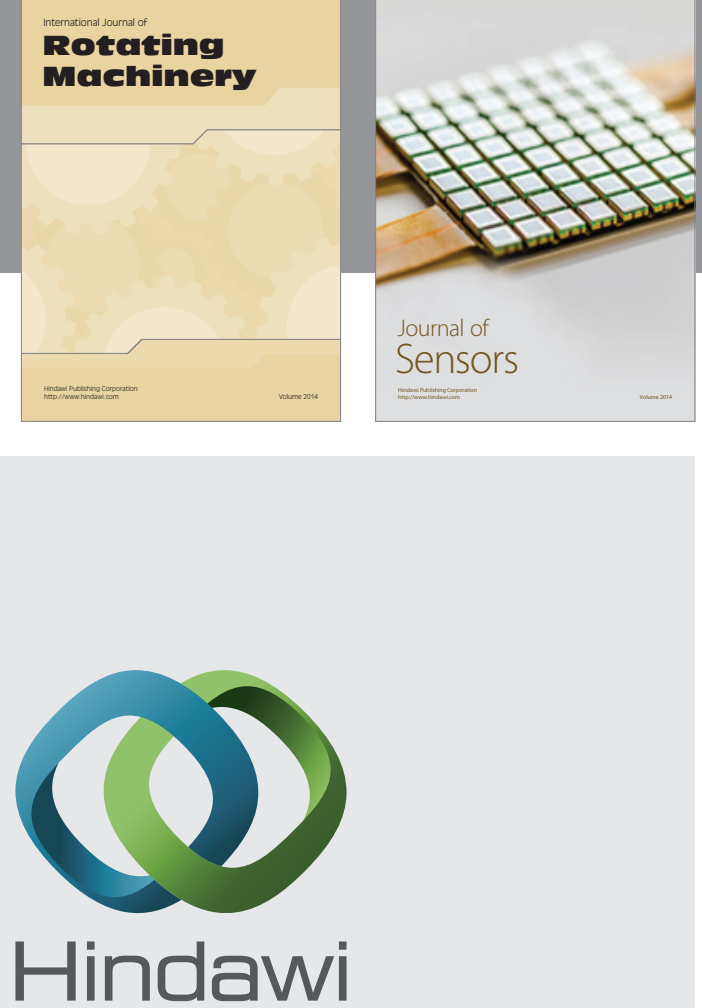

Submit your manuscripts at http://www.hindawi.com
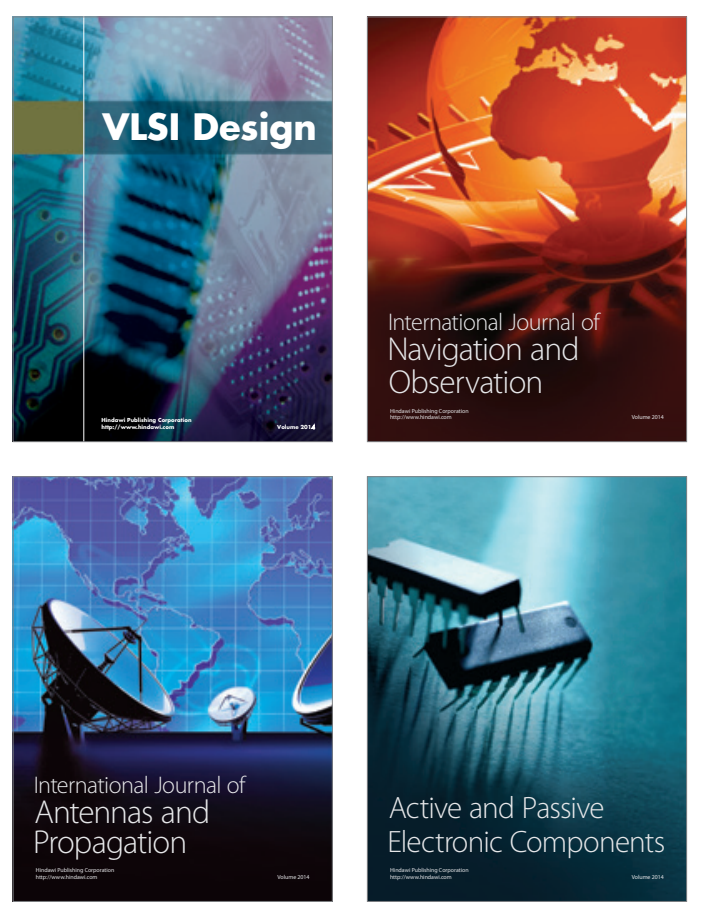
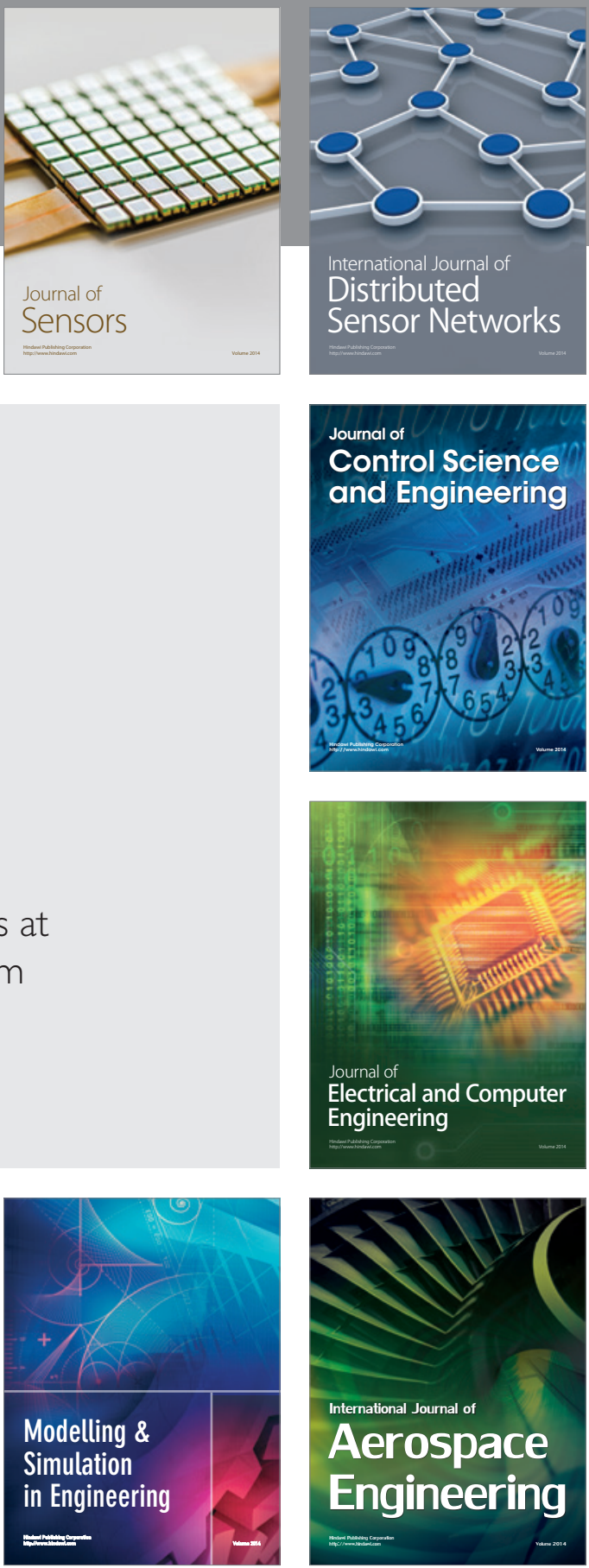

Journal of

Control Science

and Engineering
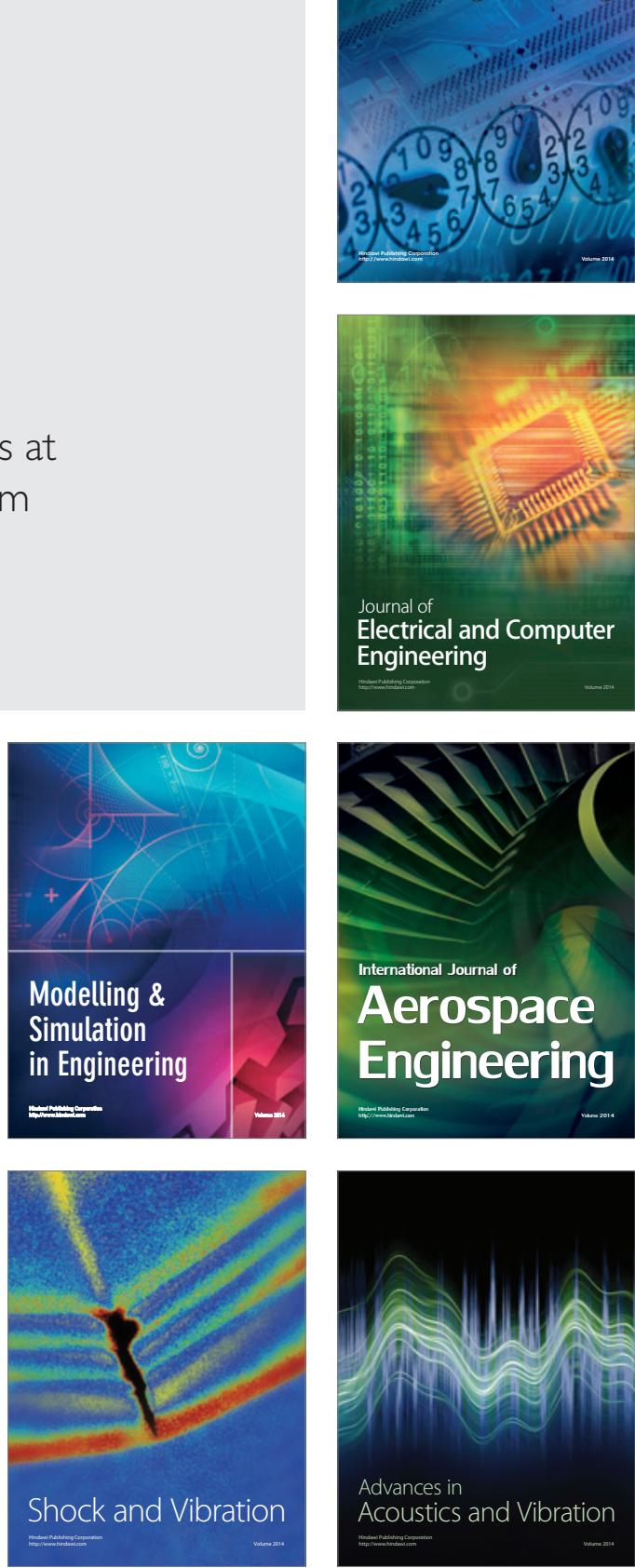